Supporting information

\title{
Immunochemical Detection of Protein Modification Derived from Metabolic Activation of 8-Epidiosbulbin E Acetate
}

Shenzhi Zhou, Na Zhang, Zixia Hu, Dongju Lin, Weiwei Li,Ying Peng, ${ }^{*}$ and Jiang Zheng*

\section{NanoLC}

Nanoflow UPLC: Ultimate 3000 system (ThermoFisher Scientific, Waltham, MA); Nanocolumn: $150 \mu \mathrm{m} \times 15 \mathrm{~cm}$ in-house made column packed with a reversed-phase ReproSil-Pur C18-AQ resin (1.9 $\mu \mathrm{m}, 100$ Å, Dr. Maisch GmbH, Germany); Loaded sample volume: $5 \mu \mathrm{L}$; Mobile phase: A: $0.1 \%$ formic acid in water, and B: $0.1 \%$ formic acid in acetonitrile; Total flow rate : $600 \mathrm{~nL} / \mathrm{min}$; LC linear gradient: 6 - $9 \% \mathrm{~B}$ for $5 \mathrm{~min}, 9$ - $14 \%$ B for $15 \mathrm{~min}, 14-30 \%$ B for $30 \mathrm{~min}, 30-40 \% \mathrm{~B}$ for $8 \mathrm{~min}$, and $40-95 \%$ B for $2 \mathrm{~min}$.

\section{Mass spectrometry}

Q Exactive ${ }^{\mathrm{TM}}$ Hybrid Quadrupole-Orbitrap ${ }^{\mathrm{TM}}$ Mass Spectrometer (Thermo Fisher Scientific, Waltham, MA); Spray voltage: $2.2 \mathrm{kV}$; Capillary temperature: $270{ }^{\circ} \mathrm{C}$; MS parameters: MS resolution: 70000 at $400 \mathrm{~m} / \mathrm{z}$; MS precursor $\mathrm{m} / \mathrm{z}$ range: 300.0 1600.0; Product ion scan range: start from $m / z$ 100; Activation Type: CID; Min. Signal Required: 1500.0; Isolation Width: 3.00; Normalized Coll. Energy: 40.0; Default Charge State: 6; Activation Q: 0.250; Activation Time: 30.000; Data dependent MS/MS: up to top 20 most intense peptide ions from the preview scan in the Orbitrap. 


\section{Figure legends}

Figure S1. ${ }^{1} \mathrm{H}-\mathrm{NMR}$ spectrum of 3-methylpyrrole 3.

Figure S2. ${ }^{1} \mathrm{H}-\mathrm{NMR}$ spectrum of 3-methylpyrroline 4.

Figuer S3. MS/MS spectrum of Sentrin-specific protease 2.

Figure S1

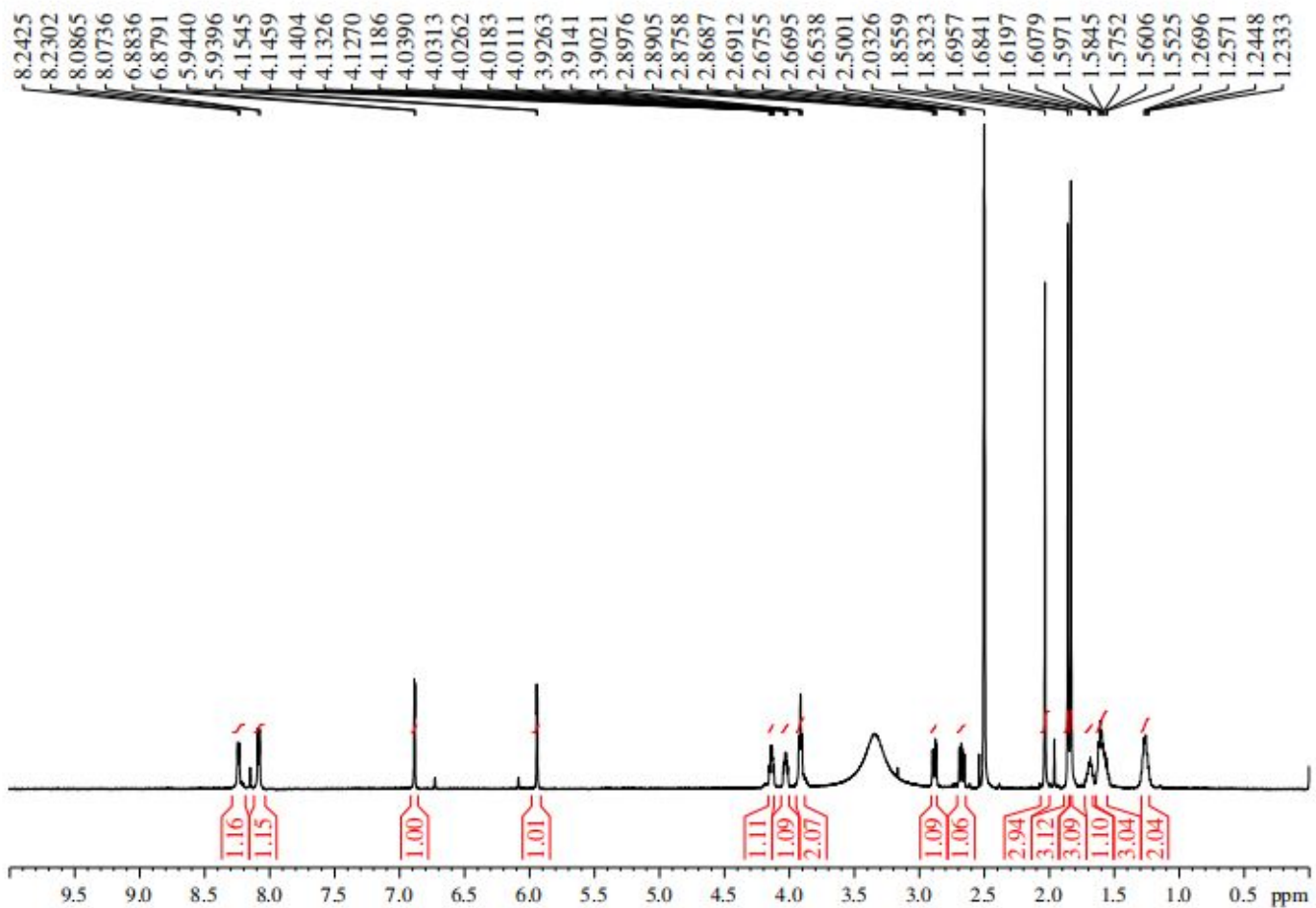


Figure S2

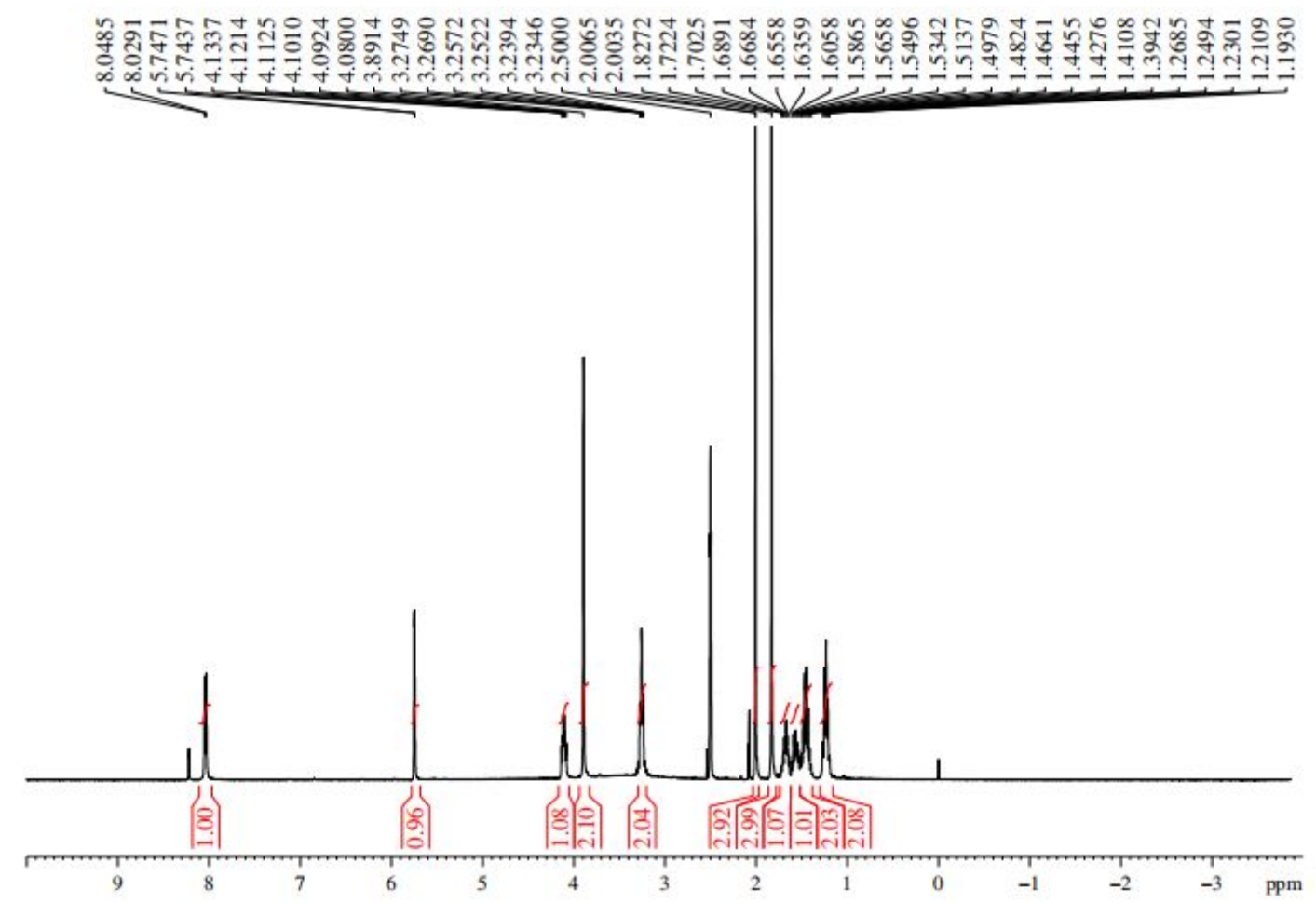


Figure S3

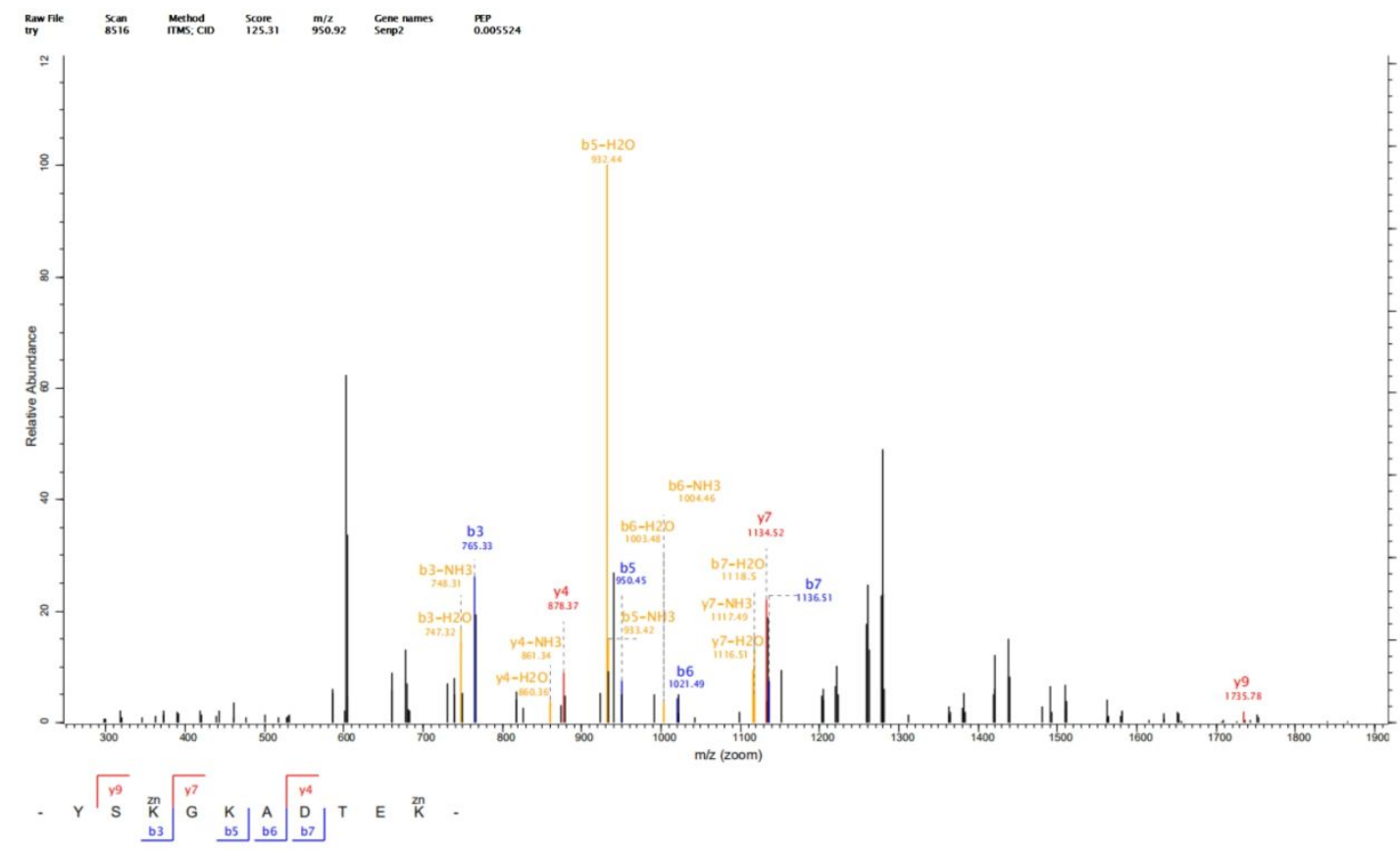

